\title{
Chromium-modified cobalt molybdenum nitrides as catalysts for ammonia synthesis
}

https://doi.org/10.1515/chem-2019-0017

received July 17, 2018; accepted October 24, 2018.

\begin{abstract}
The influence of chromium compounds on the properties of cobalt molybdenum nitrides was studied. $\mathrm{CoMoO}_{4}$ obtained by precipitation from cobalt and molybdenum salts was modified by the addition of chromium(III) nitrate. A mixture of cobalt-molybdenum nitrides, $\mathrm{Co}_{2} \mathrm{Mo}_{3} \mathrm{~N}$ and $\mathrm{Co}_{3} \mathrm{Mo}_{3} \mathrm{~N}$, was formed by ammonolysis of modified $\mathrm{CoMoO}_{4}$. The concentration of $\mathrm{Co}_{2} \mathrm{Mo}_{3} \mathrm{~N}$ decreases with increasing chromium content. The specific surface area of cobalt molybdenum nitrides consisting of $2 \mathrm{wt} \%$ of $\mathrm{Cr}$ atoms increased by $50 \%$ in comparison to pure cobalt molybdenum nitrides. The catalytic activity of obtained catalysts in ammonia synthesis process decreases with rising of chromium concentration.
\end{abstract}

Keywords: cobalt molybdenum nitride; catalyst; ammonia; chromium; promoter.

\section{Introduction}

Various forms of iron catalysts based on magnetite $[1,2]$ or wustite $[3,4]$ are still the most widely used in ammonia plants. The high energy consumption of the ammonia synthesis based on the iron catalysts is an incentive for the search of novel catalysts which will be effective at lower temperatures or under lower pressure.

\footnotetext{
*Corresponding author: Dariusz Moszyński, West Pomeranian University of Technology, Szczecin, Faculty of Chemical Technology and Engineering, Institute of Inorganic Chemical Technology and Environment Engineering, Pułaskiego 10, 70-322 Szczecin, Poland, E-mail:dmoszynski@zut.edu.pl

Paweł Adamski, Marlena Nadziejko, Agata Komorowska, Adam Sarnecki, Aleksander Albrecht: West Pomeranian University of Technology, Szczecin, Faculty of Chemical Technology and Engineering, Institute of Inorganic Chemical Technology and Environment Engineering, Putaskiego 10, 70-322 Szczecin, Poland
}

An alternative material, ruthenium supported on carbon, is already commercialized [5] and some others materials are promising e.g. cobalt molybdenum nitrides [6], carbon supported cobalt $[7,8]$, Co-Ce-Ba catalysts [9] or $\mathrm{CoRe}_{4}$ catalysts [10].

Theoretical studies have proven that cobalt molybdenum nitride, $\mathrm{Co}_{3} \mathrm{Mo}_{3} \mathrm{~N}$, is potentially the most active catalyst for ammonia synthesis [11]. Experiments have shown that cesium or potassium promoted cobalt molybdenum nitride is more active in the ammonia synthesis process than the industrial iron catalyst $[6,12$, 13]. The admixture of alkali metals has a beneficial effect on the activity of the catalyst but at the expense of a less developed porous structure and lower thermal stability $[12,14]$.

One plausible way to limit the detrimental effect of alkali metals on the specific surface area is the addition of a co-promoter. This assumption is based on the similarities between the structure and behavior of the present catalysts and iron catalysts for ammonia synthesis. In case of the latter, the admixture of aluminum or calcium oxides results in the formation of a well-developed porous structure which is a base for the active catalyst. Therefore, the proper choice of a co-promoter is crucial for the best catalytic action of the catalysts considered. In view of the model devised for the surface of iron catalyst [15] the oxides of multivalent metals can play the role of structural promoters. In this paper, the admixture of chromium compounds to cobalt molybdenum nitrides is examined and their influence on the phase composition, structural properties and catalytic activity of Co-Mo-N catalysts is studied.

\section{Experimental}

The precursor of catalysts was precipitated from hot water solutions of cobalt(II) nitrate $\mathrm{Co}\left(\mathrm{NO}_{3}\right)_{2} \cdot 6 \mathrm{H}_{2} \mathrm{O}$ and ammonium heptamolybdate $\left(\mathrm{NH}_{4}\right)_{6} \mathrm{Mo}_{7} \mathrm{O}_{24} \cdot 4 \mathrm{H}_{2} \mathrm{O}$. The 

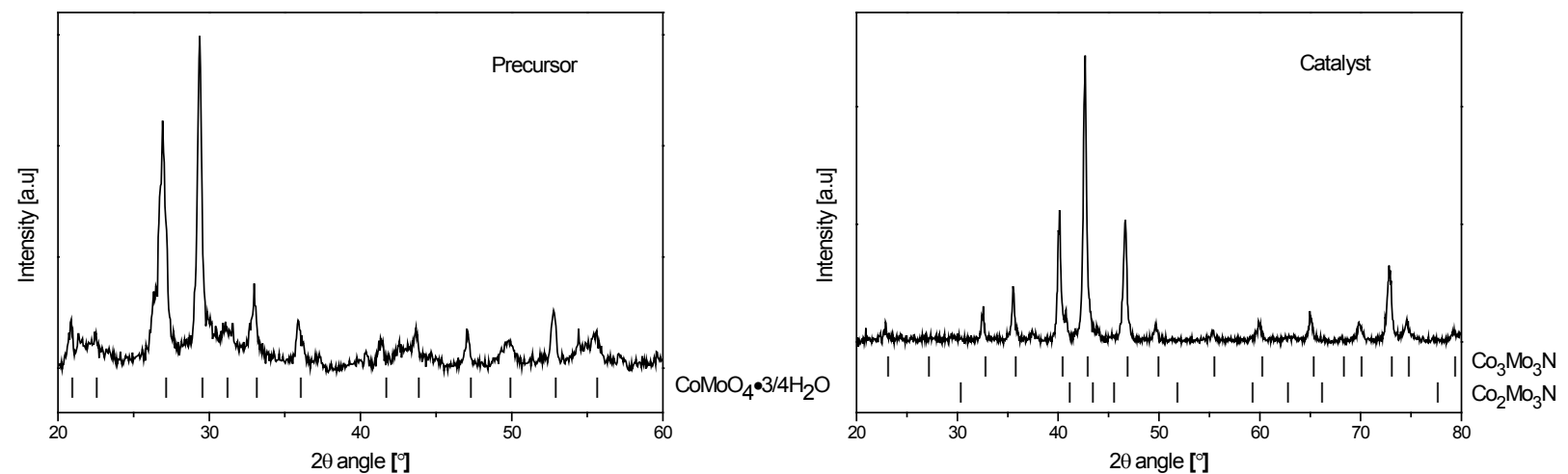

Figure 1: X-ray diffraction pattern of the precursor containing $2.0 \mathrm{wt} \%$ of chromium (left) and of the same sample after ammonolysis (right).

purple precipitate obtained via vacuum filtration was rinsed twice with distilled water and once with ethanol and then dried overnight at $150^{\circ} \mathrm{C}$. Chromium was introduced to the dry precursor by impregnation with chromium(III) nitrate $\mathrm{Cr}\left(\mathrm{NO}_{3}\right)_{3} \cdot 9 \mathrm{H}_{2} \mathrm{O}$ dissolved in distilled water. The water was removed by vacuum evaporation at $70^{\circ} \mathrm{C}$ and samples with chromium concentration between 1 and 5 wt $\%$ were prepared. The chromium-promoted precursors were reduced in a horizontal steel reactor under ammonia flow at $700^{\circ} \mathrm{C}$ for 5 hours to obtain an active form of the catalysts.

The phase composition of the obtained materials was analyzed by X-ray diffraction (XRD) using a Philips X'pert MPD diffractometer with $\mathrm{Cu} K_{\mathrm{a}}\left(\lambda_{\alpha 1}=0,154056 \mathrm{~nm}\right.$, $\left.\lambda_{\alpha 2}=0,154439 \mathrm{~nm}\right)$ monochromatized radiation. A fullpattern fit based on the Rietveld method was applied to calculate the weight fractions of the identified phases. Data required for initialization of Rietveld refinement was retrieved from the ICDD PDF-4+ database. The specific surface area of the catalysts was measured by a volumetric method utilizing the Brunauer-Emmett-Teller (BET) model with use of Quantachrome Quadrasorb SI-Kr/MP. Prior to measurements, the samples were degassed for 6 hours at $400^{\circ} \mathrm{C}$. The activity test was performed in the test setup described in details elsewhere [14]. Samples were put in separated channels of the reactor and activated under a hydrogen-nitrogen atmosphere $\left(\mathrm{N}_{2}: \mathrm{H}_{2}=1: 3 ; 0.1\right.$ $\mathrm{MPa}$ ). Activity tests were performed under $10 \mathrm{MPa}$ at $400^{\circ} \mathrm{C}$. The ammonia concentration in the outlet stream was measured by a Siemens ULTRAMAT 6 NDIR analyzer. After the first activity tests, the catalysts were kept under a hydrogen-nitrogen atmosphere (ambient pressure, $650^{\circ} \mathrm{C}$ ) for 24 hours to test their thermal stability. Subsequently, the activity test was repeated.

Ethical approval: The conducted research is not related to either human or animal use.

\section{Results and discussion}

The phase analysis of chromium-modified precursors indicates that all materials contain only cobalt molybdate hydrate, which corresponds with the $\mathrm{CoMoO}_{4} \times 3 / 4 \mathrm{H}_{2} \mathrm{O}$ structure reported elsewhere [16, 17]. Although chemical analysis proved the presence of chromium in the samples, the crystallographic phases containing chromium have not been identified. After ammonolysis, cobalt molybdate hydrate was transformed into a black product which was identified as a mixture of two crystallographic phases, both being cobalt molybdenum nitrides: $\mathrm{Co}_{3} \mathrm{Mo}_{3} \mathrm{~N}$ [18] and $\mathrm{Co}_{2} \mathrm{Mo}_{3} \mathrm{~N}$ [19]. No chromium-containing phases have been found in the active form of the catalysts. In Figure 1 X-ray diffraction patterns for the sample containing $2 \mathrm{wt} \%$ of chromium obtained before and after reduction under ammonia are presented.

Rietveld analysis was used to estimate the weight fractions of $\mathrm{Co}_{3} \mathrm{Mo}_{3} \mathrm{~N}$ and $\mathrm{Co}_{2} \mathrm{Mo}_{3} \mathrm{~N}$ phases in all prepared materials and the weight percentage of $\mathrm{Co}_{2} \mathrm{Mo}_{3} \mathrm{~N}$ is presented in Figure 2. The sample without chromium admixture contains about $18 \mathrm{wt} \%$ of $\mathrm{Co}_{2} \mathrm{Mo}_{3} \mathrm{~N}$. The admixture of chromium compounds results in a loss of the $\mathrm{Co}_{2} \mathrm{Mo}_{3} \mathrm{~N}$ weight fraction to about $4-5 \mathrm{wt} \%$ observed in the range between $2 \mathrm{wt} \%$ and $5 \mathrm{wt} \%$ of $\mathrm{Cr}$ in the catalyst. The presence of chromium atoms affects the stability of cobalt molybdenum nitrides seemingly leading to the formation of the catalysts with lower $\mathrm{Co}_{2} \mathrm{Mo}_{3} \mathrm{~N}$ content.

The catalytic activity of non-promoted cobalt molybdenum nitrides is relatively high and comparable to the activity of industrial iron catalysts [6]. Promotion with cesium or potassium compounds makes this catalyst much more active than reference iron catalysts $[6,13]$ even though the specific surface area of catalysts promoted with alkali metals is lower than non-promoted ones. The main role of chromium considered in this paper is to stimulate formation of a well-developed porous structure. Therefore, 


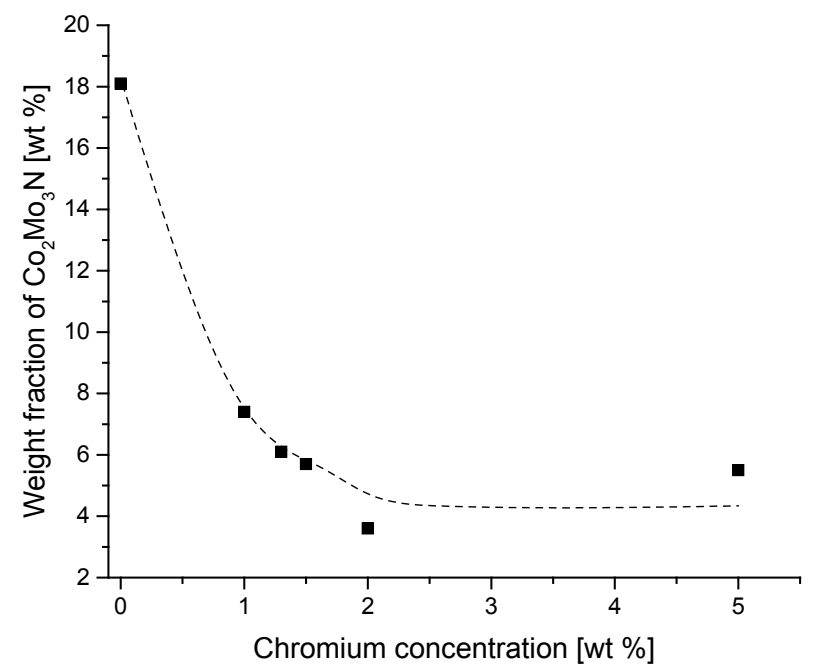

Figure 2: The weight fraction of $\mathrm{CO}_{2} \mathrm{Mo}_{3} \mathrm{~N}$ phase calculated upon XRD data as a function of chromium concentration in the sample. A dashed line is for an eye-guidance only.

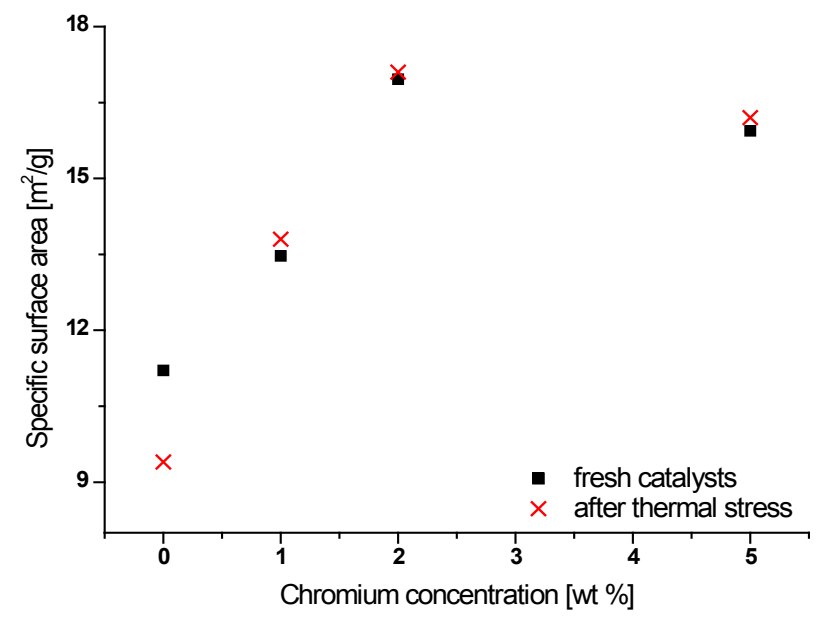

Figure 3: The specific surface area of the catalysts as a function of chromium concentration in the sample.

the beneficial influence of that promoter on the formation of the high surface area of cobalt molybdenum nitrides is a key factor of the present study. After ammonolysis, the surface area of each catalyst was measured by volumetric methods and the results are shown in Figure 3. The specific surface area of the non-promoted catalyst is about $11 \mathrm{~m}^{2} / \mathrm{g}$. The structure of chromium-promoted catalysts is better developed and their specific surface area is increased to about $17 \mathrm{~m}^{2} / \mathrm{g}$ for the sample promoted with $2 \mathrm{wt} \%$ of $\mathrm{Cr}$. In comparison to non-promoted catalyst, the surface area of the latter catalyst is about $50 \%$ higher.

Long run of a catalytic reaction usually has a detrimental effect on the porous structure of the catalyst.

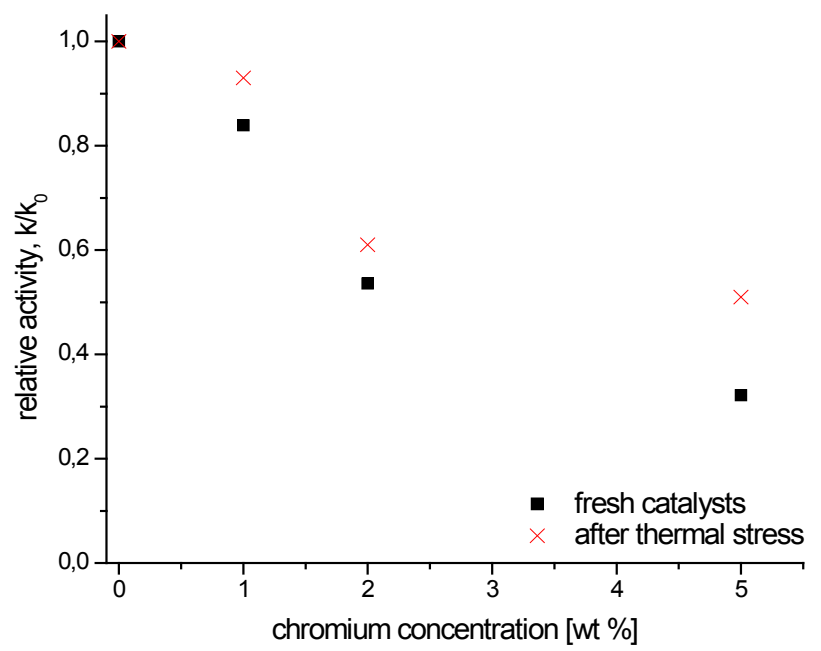

Figure 4: The activity of the catalysts as a function of chromium concentration in the sample.

Regarding the metallic catalysts, it is usually due to sintering of the crystallites and leads to the decrease of the specific surface area. This process results in a limited lifetime and thermal stability of the catalyst. Therefore, to simulate thermal stress and aging the Co-Mo-N catalysts were heated up to $650^{\circ} \mathrm{C}$ for 12 hours after the activity test. The specific surface area was measured again after repeated activity test and results are shown in Figure 3. The specific surface area of the non-promoted Co-Mo-N catalyst decreased to about $9.5 \mathrm{~m}^{2} / \mathrm{g}$. A similar effect has been reported previously for Co-Mo-N catalysts promoted with cesium [14] and was ascribed to the sintering process. The specific surface area remains stable for the catalysts promoted with chromium which indicates that the admixture of chromium compounds to Co-Mo-N catalysts not only promotes the development of the porous structure but also increases thermal stability.

The activity of the present catalysts was measured at $400^{\circ} \mathrm{C}$ during the ammonia synthesis reaction carried out under the pressure of $10 \mathrm{MPa}$. The relative activity, $\mathrm{k} / \mathrm{k}_{0}$, i.e. the activity of a specific catalyst related to the activity of the non-promoted Co-Mo-N catalyst is shown in Figure 4. Despite the significant increase of the specific surface area for the catalysts promoted with chromium, their catalytic activity is inferior in comparison to the nonpromoted Co-Mo-N catalyst. Although the surface area of the catalysts containing $2.0 \mathrm{wt} \%$ of chromium increased by $50 \%$ the catalytic activity of that catalyst is about $50 \%$ lower than the activity of the reference catalyst and catalysts with higher chromium concentration (5 wt\%) are even less active. These observations imply that the 
application of chromium compounds as the only promoter for Co-Mo-N catalysts is inefficient. However, the relative activity of chromium-modified catalysts is higher after the thermal stability test (Figure 4). In comparison to the pure cobalt molybdenum nitrides, the promoted catalysts are more stable under prolonged thermal stress.

The effect of chromium regarded herein is similar to the way the promoters like aluminum or calcium influence the properties of iron catalysts for ammonia synthesis. Their presence results in an increased thermal stability and extended lifespan of iron catalyst [1]. However, if they are used as an exclusive promoter it makes the iron catalyst virtually inactive in comparison to the iron catalyst promoted with alkali metals [20]. This effect was elucidated assuming the formation of a homogenous structure on the metal surface, in which oxygen atoms are directly bound to the iron substrate, while promoter atoms are located on the top-most layer [15]. In this layer, the relation between the number of oxygen and promoter atoms is strictly established and dependent on promoter valence state. In contrast to alkali metals which are bound to only one oxygen atom, elements like calcium or aluminum require two or three oxygen atoms in the vicinity, and as a result the whole metal surface is covered with oxygen atoms and there are no free adsorption sites. On the other hand, the presence of oxygen atoms has a beneficial effect on the formation of the surface area of the catalyst. The clean metal surface due to a high surface energy tends to sinter but the formation of metal-oxygen bonds partially balances out this trend.

Chromium nitrate added to the precursor of Co-Mo-N catalysts is transformed into chromium oxide during ammonolysis of catalysts' precursor. The presence of chromium oxides on the surface of the precursor was earlier proven by X-ray photoelectron spectroscopy (XPS) studies [17]. Since the formation of the crystallographic phases containing chromium atoms was not proven by XRD analysis it is assumed that this element mostly occupies the catalysts' surface. The effects of chromium admixture resemble the influence of calcium or aluminum in iron catalysts for ammonia synthesis. It is suggested that the main role of chromium oxide in Co-Mo-N catalysts is to change the surface energy of the system promoting the formation of a well-developed porous structure and limiting the tendency to sintering. Simultaneously the abundance of oxygen atoms, which are required to complement chromium presence on the surface, results in the reduction of the number of free adsorption sites and considerably limits the activity of the catalysts.

The main goal of the present study was achieved since chromium compounds indeed promote the development of the porous structure of Co-Mo-N catalysts. However, the materials studied herein are intended to work as a catalyst for ammonia synthesis and the inferior catalytic activity is a serious disadvantage. In view of the surface model referred to above [15], a synergetic effect of the multivalent element and alkali metal may result in the formation of a highly active catalyst with a decent surface area.

\section{Conclusions}

The admixture of chromium compounds to the catalysts based on cobalt molybdenum nitrides influences the structural and catalytic properties of these materials. With increasing chromium concentration the weight fraction of the $\mathrm{Co}_{2} \mathrm{Mo}_{3} \mathrm{~N}$ phase decreases. Although the overall catalytic activity of chromium-promoted catalysts is lower than pure cobalt molybdenum nitrides, their structural parameters are enhanced. In the promoted catalysts the specific surface area is increased by about $50 \%$. Furthermore, the thermal stability of the promoted catalysts is superior to non-promoted material.

Acknowledgments: Paweł Adamski thanks the Polish Ministry of Science and Higher Education for support through the project „Diamentowy Grant” no D12015 019445 funded in years 2016-2019.

Conflict of interest: Authors declare no conflict of interest.

\section{References}

[1] Jennings J.R., Catalytic Ammonia Synthesis, Fundamentals and Practice, Plenum Press, New York, 1991.

[2] Nielsen A., Ammonia Catalysis and Manufacture, SpringerVerlag, Berlin Heidelberg, 1995.

[3] Liu H.-Z., Li X.-N., Hu Z.-N., Developement of novel low temperature and low pressure ammonia synthesis catalyst, Appl. Catal. A: General, 1996, 142, 209-222.

[4] Liu H.-Z., Ammonia Synthesis Catalysts: Innovation and Practice, World Science Publishing Co. Ltd.. Singapore, 2013.

[5] Strait R.B., Grassroots success with KAAP, Nitrogen \& Methanol, 1999, 238, 37-43.

[6] Kojima R., Aika K., Cobalt molybdenum bimetallic nitride catalysts for ammonia synthesis Part 1. Preparation and characterization, Appl. Catal. A: General, 2001, 215, 149-160.

[7] Karolewska M., Truszkiewicz E., Wscisel M., Mierzwa B., Kępiński L., Raróg-Pilecka W., Ammonia synthesis over a Ba and Ce-promoted carbon-supported cobalt catalyst. Effect of the cerium addition and preparation procedure, J. Catal., 2013, 303, 130-134. 
[8] Tarka A., Zybert M., Truszkiewicz E., Mierzwa B., Kępiński L., Moszyński D., et al., Effect of a Barium Promoter on the Stability and Activity of Carbon-Supported Cobalt Catalysts for Ammonia Synthesis, ChemCatChem, 2015, 7, 2836-2839.

[9] Tarka A., Zybert M., Kindler Z., Szmurło J., Mierzwa B., RarógPilecka W., Effect of precipitating agent on the properties of cobalt catalysts promoted with cerium and barium for $\mathrm{NH}_{3}$ synthesis obtained by co-precipitation, Applied Catalysis A: General, 2017, 532, 19-25.

[10] McAulay K., Hargreaves J.S.J., McFarlane A.R., Price D.J., Spencer N.A., Bion N., et al., The influence of pre-treatment gas mixture upon the ammonia synthesis activity of Co-Re catalysts, Catal. Commun., 2015, 68, 53-57.

[11] Jacobsen C.J.H., Dahl S., Clausen B.S., Bahn S., Logadottir A., Norskov J.K., Catalyst Design by Interpolation in the Periodic Table: Bimetallic Ammonia Synthesis Catalysts, J. Am. Chem. Soc., 2001, 123, 8404-8405.

[12] Kojima R., Aika K., Cobalt molybdenum bimetallic nitride catalysts for ammonia synthesis Part 3. Reactant gas treatment, Appl. Catal. A: General, 2001, 219, 157-170.

[13] Moszyński D., Jędrzejewski R., Ziebro J., Arabczyk W., Surface and catalytic properties of potassium-modified cobalt molybdenum catalysts for ammonia synthesis, Appl. Surf. Sci., 2010, 256, 5581-5584.

[14] Moszyński D., Adamski P., Pełech I., Arabczyk W., Cobaltmolybdenum catalysts doped with cesium for ammonia synthesis, Przem Chem, 2015, 94, 1399-1403.

[15] Arabczyk W., Narkiewicz U., Moszyński D., Double-Layer Model of the Fused Iron Catalyst for Ammonia Synthesis, Langmuir, 1999, 15, 5785.

[16] Eda K., Uno Y., Nagai N., Sotani N., Wittingham M.S., Crystal structure of cobalt molybdate hydrate $\mathrm{CoMoO}_{4} \mathrm{nH}_{2} \mathrm{O}$, J. Solid State Chem., 2005, 178, 2791-2797.

[17] Moszyński D., Controlled phase composition of mixed cobalt molybdenum nitrides, Int J Refract Met Hard Mater, 2013, 41, 449-452.

[18] Jackson S.K., Layland R.C., Loye H.-C.z., The simultaneous powder X-ray and neutron diffraction refinement of two h-carbide type nitrides, $\mathrm{Fe}_{3} \mathrm{Mo}_{3} \mathrm{~N}$ and $\mathrm{Co}_{3} \mathrm{Mo}_{3} \mathrm{~N}$ prepared by ammonolysis and by plasma nitridation of oxide precursors, J. Alloy. Comp., 1999, 291, 94-101.

[19] Prior T.J., Battle P.D., Facile synthesis of interstitial metal nitrides with the filled b-manganese structure, J. Solid State Chem., 2003, 172, 138-147.

[20] Pernicone N., Fagherazzi G., Galante F., Garbassi F., Lazzerin F., Mattera A., The influences of oxide promoters on the properties of iron catalysts, in: J.W. Hightower (Ed.) Catalysis: Proceedings of the Fifth International Congress on Catalysis (20-26 August 1972, Miami Beach, USA),North-Holland Publishing Company, 1973,1241-1250. 